\title{
Asymptomatic Missing Cervical Plate and Screws: A Case Report
}

\author{
Guner Menekse ${ }^{\mathrm{a}, \mathrm{c}}$, Ali Ihsan Okten ${ }^{\mathrm{a}}$, Kerem Mazhar Ozsoy ${ }^{\mathrm{a}}$, \\ Tuncay Ates ${ }^{\mathrm{a}}$, Aslan Guzel ${ }^{\mathrm{b}}$
}

\begin{abstract}
Anterior cervical screw-plate system has become popular and safer in the substantial cervical spine in recent years. Materials and devices for anterior stabilization have improved in reliability. Nevertheless, screw-plate stabilization includes early and late complications. Our report demonstrates that cervical screws and plate may disappear asymptomatically or without any complication, and this is also the first case of asymptomatically disappearing cervical plate in the literature. We concluded that an esophageal perforation had occurred, and the plate and screws had been eliminated through the intestinal tract without any notice.
\end{abstract}

Keywords: Asymptomatic; Cervical spine; Complication; Esophageal perforation; Plate loss

\section{Introduction}

In recent years, degenerative, neoplastic, infections or inflammatory, traumatic and iatrogenic causes of vertebral column instability with or without concomitant neural compression are well suited for treatment with plate-screw and autolog graft fixation from an anterior surgical approach [1, 2]. The risks related to screw-plate stabilization of the cervical spine include all risks intrinsic to a routine anterior cervical corpectomy and fusion procedure; injuries to branches of the vagal nerve, dysphasia, esophageal perforation, radicular or myelopathic injury, cerebrospinal fluid leakage, infection, graft migration, postoperative hematoma, stroke and donor site morbidity, if autologous graft is used [3-5].

Manuscript accepted for publication March 31, 2014

${ }^{a}$ Department of Neurosurgery, Adana Numune Training and Research Hospital, Adana, Turkey

${ }^{b}$ Department of Neurosurgery, Faculty of Medicine, Bahcesehir University, Istanbul, Turkey

${ }^{c}$ Corresponding author: Guner Menekse, Adana Numune Egitim ve Arastirma Hastanesi, Norosirurji, Serinevler Mahallesi, Ege Bagatur Bulvari, Yuregir, 01170 Adana, Turkey. Email: gunerbc@yahoo.com

doi: http://dx.doi.org/10.14740/jmc1763w
The goals of internal fixation are to restore stability to the structurally compromised spine, to maintain alignment after correction of a deformity, to prevent the progression of a deformity and to alleviate pain. Rarely, these materials may penetrate into esophagus and eliminate through the intestinal tract [3, 5-8]. In this study, we report a late complication of displacement and loss of an anterior cervical plate and screws in an asymptomatic patient.

\section{Case Report}

A 42-year-old female presented with cervical trauma in 1998. The neurologic condition appeared to be normal. Radiographic examination of the cervical spine demonstrated a fracture line in the top end plate of C6 corpus and dislocation of C5-6 (Fig. 1A-D). Surgical treatment included anterior C6 corpectomy, anterior iliac crest graft placement and fixation using plate and screws. The immediate post-operative course was uneventful. During the 2 years of follow-up, the patient had no complains, and no changes was observed in the radiography. In 2002, cervical radiographs showed fracture of the screws and dislocation of the plate to C7-T2 levels. The patient had no clinical symptoms, and fusion response is obtained radiologically. We recommended removing plate and screws to prevent tissue injuries. However, the patient did not accept. Cervical MR investigation showed cervical fusion decompressed spinal canal and lordotic curvature. On a subsequent cervical CT in 2011, the displaced plate and screws were no longer visible. Only the broken screw in the corpus of $\mathrm{C} 7$ was seen. Whole body fluoroscopy could not identify any plate or displaced screws (Fig. 2). Barium meal swallow study showed proximally esophageal stenosis, double lumen imaging and deformity (Fig. 3A, B). Gastrointestinal tract endoscopy investigation showed stenosis was in the cervical segment, mild esophageal erosion and traction diverticula (Fig. 3C-E).

\section{Discussion}

Anterior cervical plate and screws are widely used for trau- 


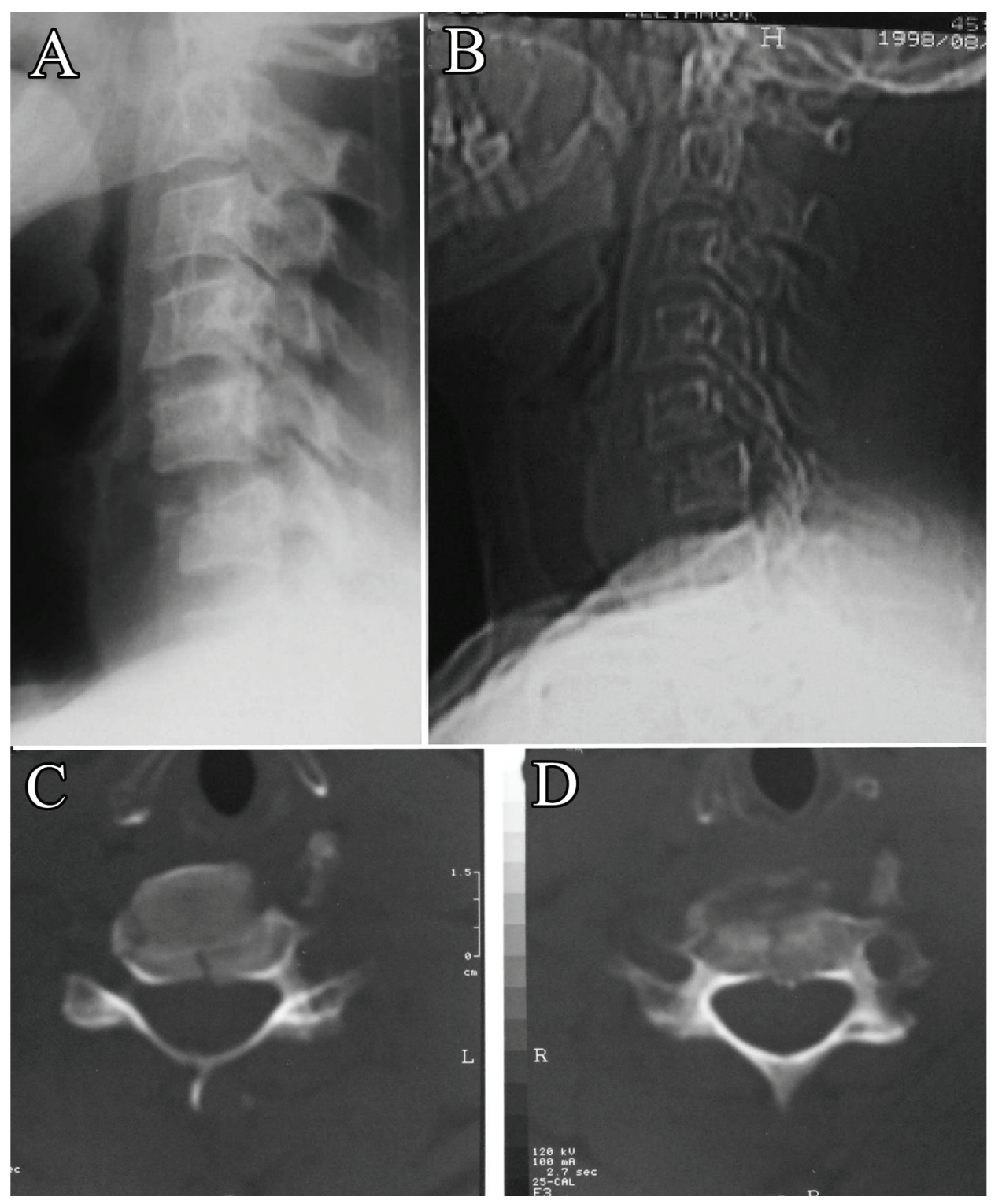

Figure 1. (A and B) The preoperative plain lateral radiograph cervical spine shows C5-6 dislocation. (C and D) axial CT scan shows fracture line.

matic, degenerative, infections and neoplastic conditions of the cervical spine $[1,2,9]$.

The reasons for morbidity and mortality due to these procedures are mainly infection, dislocation of plate-screw systems, and trachea esophagus, and vessel injuries [10,11].

Esophagus perforation due to anterior cervical approaches may lead to spontaneous healing without any notice or mortality caused by abscess, mediastinitis and sepsis [12]. Infection risk is low after cervical discectomy and fusion procedures (0.1-1.6\%). Especially, infections after 6 months of operation are very rare, and it may be associated with esophagus perforation due to displaced plate and screw systems [13]. No early and late infection was seen in the patient. Frequent symptoms due to esophagus perforation are neck and throat pain, odynophagia, dysphasia, hoarseness and aspiration. The common clinical symptoms are high fever, neck stiffness, crepitation on the anterior surface of chest and neck [14]. Gaudinez et al reported the importance of surgical treatment in esophagus perforation after anterior cervical trauma surgery. In their study, they demonstrated high morbidity and mortality rates in patients with medical treatments [14]. In our study, patient showed an asymptomatic course.

There are reports of esophageal penetration after dislocation of plate and screw systems in the literature $[3,5,15$, 16]. In 2007, Martinez et al reported the screw migration af- 


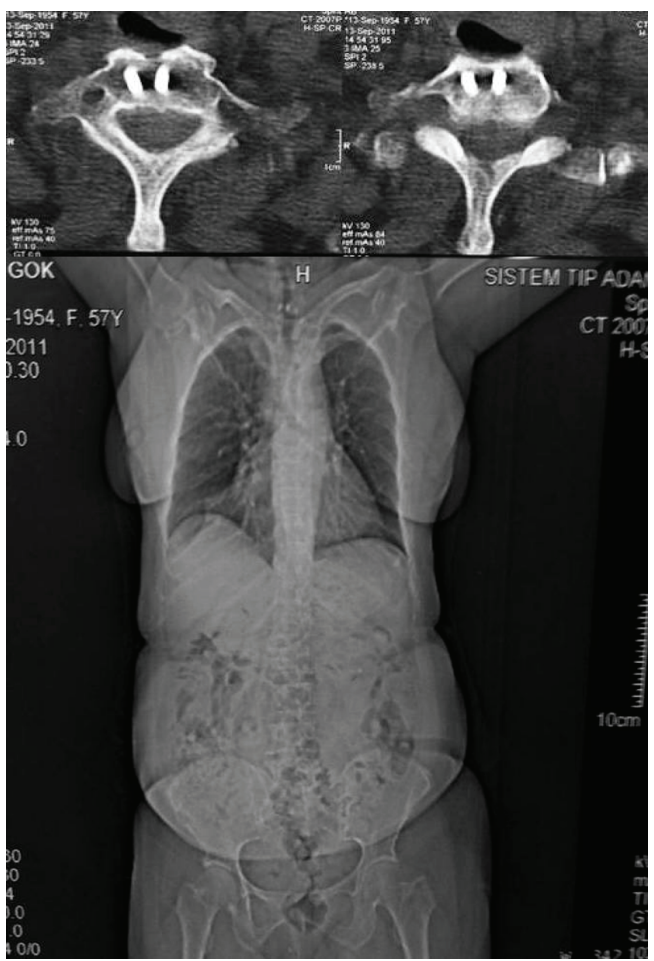

Figure 2. Axial CT scans show only broken screws in the corpus of $\mathrm{C} 7$ and whole body fluoroscopy could not identify any plate or screws. ter surgery of a C5-7 anterior decompression and fusion. Six years after surgery, the patient presented with dysphasia, and in the radiological examination, the screw could no longer be identified. Plate and screw systems were removed, and the patient was treated for prevertebral abscess secondary to esophagus perforation [8]. Gazzeri et al reported a case of spontaneous healing of esophagus fistule due to screw elimination through the intestinal tract one week after the patient complained of dysphasia and high fever [17]. Cagli et al reported cervical screw missing secondary to delayed esophageal fistula. Two years after the anterior discectomy, iliac graft placement and fixation, plate dislocation and partial migration of the upper screw were observed. After 7 years, the patient complained of dysphasia. Radiographical examination showed that one of the upper screws was missing and two lower screws were broken. Esophageal perforation was found during the removing surgery of plate, and screw systems and perforation were repaired. They concluded the screw was lost via the gastrointestinal due to spontaneous perforation of esophagus fistula [6]. Fujibayashi et al reported a case of an anterior cervical plate and screws, which were disappeared completely. The plate and screws became dislodged and eroded through the posterior wall of the esophagus, then traversed the limit of the gastrointestinal tract. But this is related to methicillin-resistant Staphylococcus aureus infection [7].

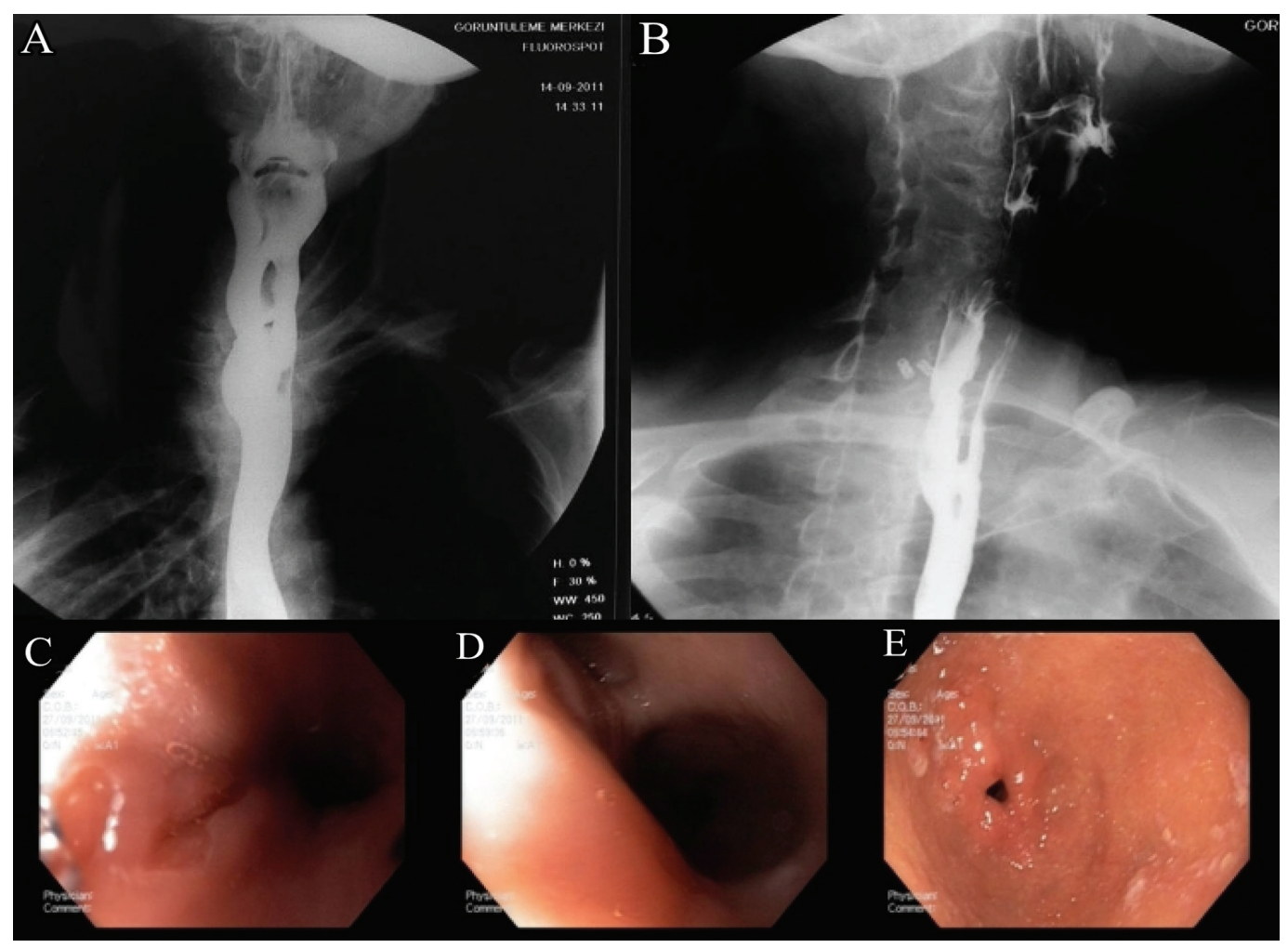

Figure 3. (A and B) Barium swallow study demonstrates proximally esophageal stenosis, double lumen imaging and deformity. (C-E) Gastrointestinal endoscopy shows stenosis in cervical segment, mild esophageal erosion and traction diverticula. 
In the literature, missing screws were described rarely. However, only one symptomatic missing plate was described. This is first case in literature with asymptomatic, missing plate and screws. We concluded that plate and screws had been eliminated thought the intestinal tract without any significant notice. Seemingly, the plate penetrates into esophagus at one side and healing process of esophagus continues on the other side. As a result of this mechanism, the plate and screws left the body without any significant defect in esophagus.

\section{Conclusion}

It can be concluded that in surgery of the cervical spine, anterior instrumentation is useful and relatively safe. Each case with displacement of plate and screws, neurosurgeons must be alert for esophageal perforation or other tissue injuries.

\section{Disclosure}

The authors declare that the article content was composed in the absence of any commercial or financial relationships that could be construed as a potential conflict of interest.

\section{References}

1. Bose B. Anterior cervical fusion using Caspar plating: analysis of results and review of the literature. Surg Neurol. 1998;49(1):25-31.

2. McCullen GM, Garfin SR. Spine update: cervical spine internal fixation using screw and screw-plate constructs. Spine (Phila Pa 1976). 2000;25(5):643-652.

3. Pompili A, Canitano S, Caroli F, Caterino M, Crecco M, Raus L, Occhipinti E. Asymptomatic esophageal perforation caused by late screw migration after anterior cervical plating. Spine. 2002;27(23):499-502.

4. Vrouenraets BC, Been HD, Brouwer-Mladin R, Bruno $\mathrm{M}$, van Lanschot JJ. Esophageal perforation associated with cervical spine surgery: report of two cases and review of the literature. Dig Surg. 2004;21(3):246-249.

5. Yee GK, Terry AF. Esophageal penetration by an anterior cervical fixation device. A case report. Spine (Phila
Pa 1976). 1993;18(4):522-527.

6. Cagli S, Isik HS, Zileli M. Cervical screw missing secondary to delayed esophageal fistula: case report. Turk Neurosurg. 2009;19(4):437-440.

7. Fujibayashi S, Shikata J, Kamiya N, Tanaka C. Missing anterior cervical plate and screws: a case report. Spine (Phila Pa 1976). 2000;25(17):2258-2261.

8. Martinez-Lage JF, Felipe-Murcia M, Martinez-Lage Azorin L. Late prevertebral abscess following anterior cervical plating: the missing screw. Neurocirugia (Astur). 2007;18(2):111-114.

9. Caspar W, Barbier DD, Klara PM. Anterior cervical fusion and Caspar plate stabilization for cervical trauma. Neurosurgery. 1989;25(4):491-502.

10. Lowery GL, McDonough RF. The significance of hardware failure in anterior cervical plate fixation. Patients with 2- to 7-year follow-up. Spine (Phila Pa 1976). 1998;23(2):181-186; discussion 186-187.

11. Schultz KD, Jr., McLaughlin MR, Haid RW, Jr., Comey $\mathrm{CH}$, Rodts GE, Jr., Alexander J. Single-stage anteriorposterior decompression and stabilization for complex cervical spine disorders. J Neurosurg. 2000;93(2 Suppl):214-221.

12. Bohlman HH. Complications of treatment of fractures and dislocations of the cervical spine. In: Complications in Orthopedic Surgery, vol. 2. Philadelphia: JB Lippincott; 1986;681-712.

13. Christiano LD, Goldstein IM. Late prevertebral abscess after anterior cervical fusion. Spine (Phila Pa 1976). 2011;36(12):E798-802.

14. Gaudinez RF, English GM, Gebhard JS, Brugman JL, Donaldson DH, Brown CW. Esophageal perforations after anterior cervical surgery. J Spinal Disord. 2000;13(1):77-84.

15. Chataigner H, Gangloff S, Onimus M. Elimination spontanee de vis d'osteosynthese cervicale anteieure par les voices naturelles: A propos d'un cas. Rev Chir Ortop. 1997;83(1):78-82.

16. Smith MD, Bolesta MJ. Esophageal perforation after anterior cervical plate fixation: a report of two cases. J Spinal Disord. 1992;5(3):357-362.

17. Gazzeri R, Tamorri M, Faiola A, Gazzeri G. Delayed migration of a screw into the gastrointestinal tract after anterior cervical spine plating. Spine (Phila Pa 1976). 2008;33(8):E268-271. 